\title{
IMPROVED PHENOL ADSORPTION ON CARBONS AFTER MILD TEMPERATURE STEAM REACTIVATION
}

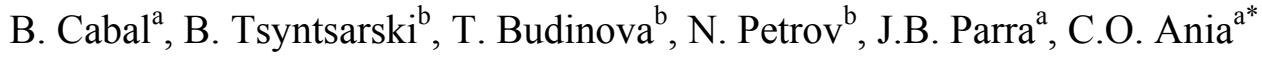 \\ ${ }^{a}$ Instituto Nacional del Carbon, CSIC, Apartado 73, 33080 Oviedo, Spain \\ ${ }^{b}$ Institute of Organic Chemistry, Bulgarian Academy of Sciences, Acad. G. Bonchev Str. \\ B1. 9, 1113 Sofia, Bulgaria
}

\begin{abstract}
The purpose of this work is to explore steam reactivation at moderate temperatures of activated carbon exhausted with phenol, a highly toxic compound frequently present in industrial wastewater. The spent carbon was treated with steam at various temperatures $\left(450,600\right.$ and $850^{\circ} \mathrm{C}$ ) and times (from 5 to $60 \mathrm{~min}$ ). Promising results were obtained by applying moderate temperatures and times. Whereas at low temperatures the complete regeneration of the carbon is not accomplished, an almost quantitative desorption of the pollutant was achieved at $600^{\circ} \mathrm{C}$ after exposure times below $30 \mathrm{~min}$, with minimal damages in the porous network of the carbon. Further reutilization of the regenerated carbon resulted in a superior performance towards phenol uptake. The regeneration efficiency at $850{ }^{\circ} \mathrm{C}$ strongly depends on the time of reactivation, with an enhanced phenol uptake when short treatment times are applied. Prolonged duration of the regeneration treatment reduced phenol adsorption capacities, due to overreactivation of the carbon in the steam atmosphere, and to the blockage of the porous carbon network.
\end{abstract}

Keywords: adsorption, phenol, steam regeneration, moderate temperatures

* corresponding author. Current address: INCAR, CSIC, C/ Francisco Pintado Fe 26, 33011 Oviedo, Spain; Tel.: 0034 985119090; Fax: 0034985297662.

E-mail address: conchi@incar.csic.es (CO Ania) 


\section{Introduction}

Faced with an increasing contamination of water resources, adsorption has become a well-established technique to remove pollutants, activated carbon (AC) being the prevailing adsorbent for the purification of water with low pollutant concentration [1]. Formerly, when an AC reached its saturation limit, it was usually taken to a landfill and dumped. However, the enclosing and burying of hazardous waste is becoming unacceptable due to growing concern about the effect of pollutants on the environment and the development of more restrictive environmental regulations. Currently, the loaded carbon is regenerated off-site by heating or steaming in large industrial facilities, which is a high-energy consuming process and a costly procedure. This has encouraged industries to seek for alternative low cost solutions for regenerating and reusing the exhausted adsorbents.

Over the years, a wide variety of regeneration techniques have been suggested and applied. They are based either on desorption - induced by increasing the temperature (using steam, carbon dioxide or inert atmosphere) or by displacement with solvents ( $\mathrm{pH}-$ swing or extraction with solvents)- or on decomposition induced by thermal, chemical, catalytic or microbiological processes [2-12]. An overview about regeneration methods can be found in [4].

The efficiency of the different regeneration processes of activated carbons largely depends on the following factors: the porous structure of the carbon and the chemical condition of its surface; the physico/chemical properties of the adsorbent; the methods applied for regeneration, and the conditions under which the regeneration process is conducted [2-12]. Although thermal reactivation is a highly skilled process that ensures that spent carbon is returned to a reusable quality, there is a major issue concerning the economic costs of the reactivation of the spent material. Despite the regeneration efficiency is relatively high, there is a considerable mass loss of activated carbon [13] after successive heating and cooling cycles, and very often there is a significant deterioration of the adsorbent's pore structure, thereby reducing the final adsorption capacity and the efficiency of the regeneration $[5,6]$. 
Previous studies $[5,6,14]$ have been focused on investigating the thermal regeneration of carbons saturated with phenol, using inert and $\mathrm{CO}_{2}$ atmosphere, and exploring the effect of different heating mechanisms (conventional vs. microwave assisted-heating) on the porosity and adsorption performance. Subsequent cycles of regeneration under oxidizing atmosphere at the typical temperatures $\left(850^{\circ} \mathrm{C}\right)$ caused a collapse of the porosity, due to the formation of coke residues and non-quantitative desorption of the adsorbate. On the other hand, microwave-assisted reactivation implies a lower consumption of gas and energy; at the same time microwave heating increased the regeneration efficiencies over a larger number of cycles.

The main objective of this research is to explore the application of steam reactivation treatments for the regeneration of an activated carbon bed loaded with phenol, a common persistent organic pollutant in industrial effluents. The efficiency of the reactivation process and its impact on the further performance of the adsorbent upon several cycles was carefully investigated. Special attention was paid to the effect of the reactivation temperature on the regeneration efficiency, aiming to reduce its typically high energy consumption (thermal energy). The nanotextural changes induced in the adsorbent after several cycles, which affect the complex process of adsorption from diluted solutions, were also investigated.

\section{Experimental}

\subsection{Materials}

A commercial powdered activated carbon Q, supplied by Agrovin SA, which is obtained from steam activation of coal, was chosen for this study. This adsorbent is commonly used for the purification of industrial wastewater and drinking water. Before the experiments the as-received carbon was soaked in a Soxhlet apparatus with distilled water to remove soluble components, dried at $120^{\circ} \mathrm{C}$ overnight and stored in a desiccator until use. Chemical composition of the as-received carbon is shown in Table 1.

\subsection{Saturation of the activated carbon bed}

Details on the experimental equipment used have been described elsewhere [4]. Briefly, rapid small-scale column tests were used for the evaluation of the adsorptive capacity. 
Breakthrough curves were obtained at $30{ }^{\circ} \mathrm{C}$ in columns packed with ca. $0.5 \mathrm{~g}$ of activated carbon. All the experiments were conducted at an initial concentration of $2 \mathrm{~g} \mathrm{~L}^{-1}$, and a flow rate of $4 \mathrm{~cm}^{3} \mathrm{~min}^{-1}$. The outlet concentration was continuously monitored using a UV-VIS spectrophotometer at the corresponding wavelength $(269 \mathrm{~nm})$. The adsorptive capacities were obtained by integrating over the entire breakthrough curve. When the saturation point was reached, the exhausted AC was washed with distilled water for $30 \mathrm{~min}$ in order to eliminate any excess of pollutant, and dried overnight at $120{ }^{\circ} \mathrm{C}$ to reduce the moisture content. Afterwards, the sub-samples of the exhausted AC were regenerated.

\subsection{Steam reactivation}

Regeneration of the exhausted carbon was carried out in a conventional electric furnace connected to a steam boiler. For each reactivation, about $1 \mathrm{~g}$ of the dried spent carbon was treated at a time. The spent $\mathrm{AC}$ was placed in a quartz reactor and purged with inert gas. The sample was then heated using a nitrogen flow rate of $10 \mathrm{~mL} \mathrm{~min}{ }^{-1}$. The inert atmosphere was maintained during the heating up and cooling-down intervals. The exhausted samples were reactivated at different temperatures: 450,600 and $850{ }^{\circ} \mathrm{C}$, varying the exposure time $(5,15,30,60 \mathrm{~min})$. Samples will be denoted as $\mathrm{Q}$ followed by a reference to the temperature and the time (i.e., Q600-15). The effect of the heating mechanism in the absence of the adsorbate was also evaluated; the blanks will be denoted as $\mathrm{B}$ followed by the reference for the temperature and time (i.e., B600-15). The efficiency of regeneration will be discussed in terms of the phenol adsorption capacity of the reactivated samples, compared to that of the fresh activated carbon.

\subsection{Textural and chemical characterization}

Textural characterization was carried out by measuring the $\mathrm{N}_{2}$ adsorption isotherms at $-196{ }^{\circ} \mathrm{C}$ in an automatic apparatus (Tristar 3000 from Micromeritics). Before the experiments, the samples were outgassed under vacuum at $120{ }^{\circ} \mathrm{C}$ overnight. The isotherms were used to calculate the specific surface area $S_{\mathrm{BET}}$, total pore volume $V_{\mathrm{T}}$, and micropore volume $\mathrm{W}_{\mathrm{o}}$, using the DR equation [15]. The mean pore size $\mathrm{L}$ was evaluated from the Stoeckli-Ballerini equation [16], as $\mathrm{L}=10.8 /\left(\mathrm{E}_{0}-11.4\right)$. The micropore surface area $\mathrm{S}_{\mathrm{mic}}$, was evaluated according to the equation $\mathrm{S}_{\mathrm{mic}}=2 \mathrm{~W}_{0} / \mathrm{L}$ [17]. Additionally, the 
narrow microporosity (pore width smaller than $0.7 \mathrm{~nm}$ ) was estimated from $\mathrm{CO}_{2}$ adsorption isotherms at $0{ }^{\circ} \mathrm{C}$, using $1.023 \mathrm{~g} \mathrm{~cm}^{-3}$ as the density of adsorbed $\mathrm{CO}_{2}$ and 0.36 as $\beta$ parameter.

The as-received, exhausted $\mathrm{Q}$ and reactivated samples were further characterized by thermal analysis, using a TA Instrument thermal analyzer. The instrument settings were heating rate $10{ }^{\circ} \mathrm{C} \mathrm{min}^{-1}$ and nitrogen atmosphere with $50 \mathrm{~cm}^{3} \mathrm{~min}^{-1}$ flow rate. For each measurement about $25 \mathrm{mg}$ of carbon sample was used. The carbon samples were also analyzed by FTIR spectroscopy. Infrared spectra were recorded in a Nicolet Magna IR 560 spectrometer with a high-sensitivity MCT/A detector. The spectra were recorded in diffuse reflectance mode (DRIFTS). Each spectrum was obtained by collecting 300 interferograms with $4 \mathrm{~cm}^{-1}$ resolution. The chemical composition of the activated carbons was determined in a LECO CHNS-932 analyzer. Oxygen content has been directly measured in a LECO VTF-900 analyzer. The point of zero charge was determined by the mass-titration method [18].

\section{Results and discussion}

\subsection{Effect of steam pyrolysis on the non-exhausted (blank) carbons}

Since steam activation addresses for two key features -carbon gasification and regeneration-, an important question to consider is the effect of the steam activation on the non-saturated (as-received) carbon. Any modification of the porosity of the raw material would have an important consequence on the later adsorption performance of the resulting material. Detailed characteristics of the pore structure of the as-received carbon after steam pyrolysis are summarized in Table 2.

Steam activation at 450 and $600{ }^{\circ} \mathrm{C}$ of the non-saturated materials does not change significantly the surface area or the pore volumes, regardless the duration of the reactivation treatment. Steam gasification of carbons requires high temperatures to achieve an elevated kinetic constant [19,20]; with the times used in this work, the modifications observed in the porosity of the blanks should not be attributed to the creation of new porosity. This was further corroborated by the similar values of micropore volumes $\mathrm{W}_{0}, \mathrm{CO} 2$ as compared to the as-received sample. Hence, minor 
modifications observed are attributed to a somewhat collapse of the pore walls as a consequence of the heat treatment (structural annealing) $[5,21]$.

The samples submitted to steam reactivation at $850{ }^{\circ} \mathrm{C}$ followed different trends. In this case the structural annealing of the carbon takes place to a large extent, due to the high temperature; at the same time it appears that the temperature is high enough to provoke to some extent - the gasification of the carbon. Although 5 min treatment is too short to produce changes in the porosity, after 15 min the gasification of the sample cannot be neglected and brings about an effect of open microporosity - the average pore size increased from 1.4 up to $2 \mathrm{~nm}$. The surface areas and pore volumes increased with the time of the steam reactivation.

On the other hand, thermal analysis was also carried out on the blank series of carbons in order to determine whether the steam reactivation modifies the chemical composition of the activated carbons. The formation of surface oxide as a consequence of the oxidative nature of steam, has been reported during gasification in water vapor [20, 22]. DTG profiles of the blanks (Fig. 1a) showed that steam pyrolysis at 450 and $600{ }^{\circ} \mathrm{C}$ does not incorporate surface functional groups on the carbon, regardless the time of the process. In contrast, when steaming at $850{ }^{\circ} \mathrm{C}$ is applied during 30 and 60 min the carbon is slightly oxidized, as it can be inferred from the peaks that appear around $200-350^{\circ} \mathrm{C}$ (Fig. 1a). Notwithstanding the extent of oxidation may be considered low, since the mass loss corresponding to the evolution of surface functionalities is in all cases below $5 \%$ (i.e., the mass loss at temperatures below $500{ }^{\circ} \mathrm{C}$ after moisture correction accounts for 3 and $4 \%$ in $\mathrm{B} 850-30$ and $\mathrm{B} 850-60$, respectively). The values of the $\mathrm{pH}$ of the point of zero charge $\left(\mathrm{pH}_{\mathrm{PZC}}\right)$ of the blanks (Table 2$)$ also confirm this observation. This contrasts with the large mass loss of the carbon after phenol retention -Qexh- (Table 3).

\subsection{Steam reactivation of the exhausted carbons}

Although steam reactivation techniques have been widely explored and reported in the literature $[10,11]$ most of the works focus on the removal of gaseous pollutants which low boiling point allows to use low regeneration temperatures. The challenges in the case of phenol are manifold: on the one hand, phenol is a highly toxic and carcinogenic compound, and therefore activated carbon beds saturated with this probe should be 
handled as a hazardous waste; on the other hand, studies on the mechanism of phenol retention on activated carbons have shown that it is a complex one and that adsorption may take place [23-28] in different active sites (physisorption and chemisorption), and it strongly depends on the carbon porosity and surface chemistry, and the solution conditions that influence the solution stability and phenol ionization state. Despite its apparently low boiling point (slightly above $180^{\circ} \mathrm{C}$ ), phenol is not easily desorbed from activated carbons.

Figure 2 shows the DTG profiles of the carbon after phenol exposure (Q exh). The complex mechanism of adsorption is evidenced by the presence of several desorption peaks, that confirms the different types of interactions between adsorbed phenol molecules and the carbon surface. These peaks are attributed to phenol retained in different active sites (or conformations) on the surface of the activated carbon and/or to the thermal decomposition of phenol due to a catalytic effect of the carbon surface, since they are not observed in the non-saturated material (Figure 1b). The mass loss at temperatures around $100{ }^{\circ} \mathrm{C}$, observed in all the carbons, is assigned to desorption of moisture. The second peak centered at about $250^{\circ} \mathrm{C}$ can be assigned to the release of physisorbed phenol $[14,24]$. The three desorption peaks at higher temperatures $(420,560$ and $720^{\circ} \mathrm{C}$ ) are due to chemisorbed phenol molecules $\left(420\right.$ and $\left.560^{\circ} \mathrm{C}\right)$, confirming the multiple interactions of phenol molecules with the carbon surface (i.e., active sites of increasing adsorption energy). The high temperature peak might $\left(720^{\circ} \mathrm{C}\right)$, also be due to the thermal decomposition of phenol molecules remaining in the pores. The ratio of chemisorbed phenol molecules exceeds that of the physisorbed species, especially for the peak centered at $420^{\circ} \mathrm{C}$. This fact contrasts with previous findings reported in the literature [14,24] for diluted solutions and thus may be linked to the high initial concentration of the phenol solution $\left(2000 \mathrm{mg} \mathrm{L}^{-1}\right)$ used in this work.

The chemisorption of phenol (also known as irreversible adsorption) has been the object of plentiful studies and a number of mechanisms have been proposed -oxidative coupling, formation of different complexes between phenol molecules and the carbon surface, catalytic polymerization in the presence of free radicals on the carbon surface [26-28]-. Most of these mechanisms point out the outstanding role of basic properties of activated carbons on irreversible adsorption. This is in good agreement with our observations 
concerning the large proportion of irreversible adsorption, since Q carbon possess a basic nature $\left(\mathrm{pH}_{\mathrm{PZC}} 9.2\right)$.

By comparing the fraction of desorbed phenol molecules with the temperature and time of reactivation, it is observed that the thermal treatment in steam atmosphere removes only part of the adsorbed phenol. At $450{ }^{\circ} \mathrm{C}$, the reactivation of the carbon appears to be limited to a certain extent; the mass loss from DTG analysis - corresponding to the nondesorbed species during the reactivation - reaches a maximum between 5-6\% after $30 \mathrm{~min}$. The increase in the reactivation time does not yield any further increase in the amount desorbed. This suggests that the temperature is not high enough to achieve complete desorption of the irreversibly retained molecules. This is confirmed by the DTG, which shows that the physisorbed molecules (i.e., the peak at $260{ }^{\circ} \mathrm{C}$ ) are completely removed after reactivation at $450{ }^{\circ} \mathrm{C}$; the largest peak centred at $425{ }^{\circ} \mathrm{C}$ decreased and disappeared almost completely, whereas there is a large contribution of chemisorbed phenol (peaks at 560 and $720^{\circ} \mathrm{C}$, respectively/) that remains inside the porous network of the carbon. Steaming at $600{ }^{\circ} \mathrm{C}$ yields a more quantitative desorption; the mass loss corresponding to 15 and $60 \mathrm{~min}$ of reactivation is 3.5 and $2.2 \%$, respectively.

Analysis of the effluent gases evolved from the TGA of the exhausted carbon -Q exhshowed that water, phenol and small amounts of $\mathrm{CO}_{2}$ are desorbed below $600{ }^{\circ} \mathrm{C}$. This suggests that at moderate regeneration temperatures (ca. 450 and $600{ }^{\circ} \mathrm{C}$ ) phenol is mainly desorbed in a molecular form -which is in good agreement with reported data on thermal degradation of free phenol starting above $665^{\circ} \mathrm{C}[29]-$, confirming catalytic effects for phenol degradation at low temperatures can be neglected. Thus, the decomposition of phenol molecules inside the porosity of the adsorbent leading to blockage of the pores by formation of carbonaceous coke deposits $[5,30]$ would not be occurring at these temperatures.

Nevertheless, it can be seen from DTG profiles that at such low temperatures desorption is non-quantitative, therefore some of the active sites for phenol adsorption would still remain somewhat blocked. Expectations are confirmed by FTIR and analysis of the porosity of the reactivated carbons. 
As an example, FTIR spectra of the samples regenerated at $850{ }^{\circ} \mathrm{C}$ are shown in Figure 3. Data concerning the treatment at 450 and $600{ }^{\circ} \mathrm{C}$ showed a similar behavior (not shown). The spectrum of solid phenol has also been included for comparison. A broad band centred at $3200 \mathrm{~cm}^{-1}$ appears after phenol exposure (sample Q exh). It has been assigned to O-H stretching modes in phenol molecules [31] as it is also observed in the spectrum of solid phenol but does not appear in the non-saturated carbon. Regeneration of the carbon results in a gradual decrease in the intensity of this band, confirming a partial removal of the retained phenol molecules.

\subsubsection{Characterization of the regenerated carbons}

The steam reactivation did not modify the basic nature of the as-received carbon, as evidenced by the values of the $\mathrm{pH}_{\mathrm{PZC}}$ corresponding to the blank series (Table 2). In contrast, the $\mathrm{pH}$ of the exhausted carbon decreased by $2 \mathrm{pH}$ units (Table 4). As long as the reactivation time and temperature are increased, the $\mathrm{pH}_{\mathrm{PZC}}$ of the regenerated carbons rises gradually as the extent of desorption increases. This demonstrates that the fall in $\mathrm{pH}$ in the exhausted carbon -Qexh- is due to the adsorbed phenol molecules, and that basic nature of the reactivated samples is not modified due to the steam reactivation. Thus, the differences in the phenol adsorption capacities of the reactivated samples must be understood in terms of the changes in the porosity.

It is clearly seen in Table 4 that the samples reactivated at $450{ }^{\circ} \mathrm{C}$ posses a large deterioration of the porosity; the surface area and pore volumes decrease more than $50 \%$, regardless of the duration of the regeneration treatment. As discussed above, this is due to the low temperature; samples reactivated at $450{ }^{\circ} \mathrm{C}$ present larger values of the $\mathrm{L}$ parameter, which indicates the presence of micropores of larger sizes. This finding also points out that most of the narrow micropores remain inaccessible, and it is in good agreement with the sharp decrease in the narrow micropore volume obtained from $\mathrm{CO}_{2}$ adsorption isotherms. The blockage of the narrow microporosity has outstanding implications in phenol adsorption, as it is shown in Figure 4 by the lower performance of the carbons treated at $4500^{\circ} \mathrm{C}$.

Reactivation at $600{ }^{\circ} \mathrm{C}$ appeared to be more advantageous. After 30 min the recovery of the structural parameters is satisfactory, particularly the micropore volumes. The decrease 
in the surface area is also less pronounced (between 15-30\%). Due to the higher temperature, desorption appeared to be more quantitative when compared to steaming at $450{ }^{\circ} \mathrm{C}$, whereas the temperature is still low enough to prevent decomposition of phenol molecules. Combination of both effects contributes to minimize the damage to the porosity (i.e., pore volumes) in the reactivation process.

As regards phenol uptake, a slightly higher retention is obtained in the samples treated at $600{ }^{\circ} \mathrm{C}$ during 15 and $30 \mathrm{~min}$. To understand this behaviour the textural parameters should be analysed in detail. It appears that micropores become narrower during the steam treatment, as inferred from the $\mathrm{CO}_{2}$ adsorption data. Despite that the pore volumes of the reactivated samples are slightly lower, the amount of $\mathrm{CO}_{2}$ adsorbed by the samples treated during 30 and $60 \mathrm{~min}$ at $600{ }^{\circ} \mathrm{C}$ is a higher at low relative pressures than that in the raw carbon Q (Figure 5). This behaviour is indicative of the presence of larger amount of pores of smaller sizes.

It is well known that phenol retention occurs preferably at micropores of small sizes $[4,6,25]$, therefore in good agreement with our observations the phenol uptake is expected to increase with the fraction of the narrow micropores. A similar behaviour of higher phenol adsorption capacities on microwave-assisted regenerated samples has been previously observed $[5,6]$. As for the narrowing effect, this could be due to some kind of internal reorganization of the carbon structure upon steaming (similar trend is obtained for the blanks, see Table 2), and/or of the non-desorbed molecules.

When the temperature is increased up to $850^{\circ} \mathrm{C}$, the normal operating parameter in industrial reactivation facilities, we observed important changes in the porosity and performance of the carbons. After $5 \mathrm{~min}$, a large amount of phenol is desorbed (about $50 \%$ upon calculation form the mass loss in the DTG profiles), but still a large fraction remains inside the porosity; those phenol molecules which are not removed may decompose inside the porous network in the form of light gases and heavy products [14], due to the high temperature of the processes, thus creating pore constrictions (Table 4). As a result, the adsorption capacity of the sample after 5 min regeneration at $850{ }^{\circ} \mathrm{C}$ is lower than that of the fresh carbon (Figure 5).

When the sample is treated for longer times (15 and $30 \mathrm{~min})$, DTG profiles confirm that most of phenol molecules are evolved. The porosity of these samples recovers almost 
completely (Table 4) and phenol uptake is higher than the capacity attained in the raw carbon. This is explained in terms of the changes in the porosity due to the structural annealing and phenol decomposition $[9,30,32]$. As a consequence of the formation of coke deposits within the pore structure, surface area the micropore distribution shifts towards narrower pores, thereby favouring a higher phenol uptake.

Similar observations have been reported after treatment at $850{ }^{\circ} \mathrm{C}$ under inert atmosphere and microwave-assisted regeneration $[5,6]$. After 60 min treatment, the overreactivation of the carbon is too high and produces an enlargement of the micropores (widening) that is unfavourable for phenol uptake. Thus, the retention decreases, although it still outperforms the retention of the raw carbon.

\section{Conclusions}

Activated carbon regeneration technologies based on various steam treatments were investigated to select the most advantageous method for minimizing carbon damages while preserving good performances. Significant energetic savings of the mild temperature steam reactivation of carbons, exhausted with phenol are demonstrated.

The most interesting reactivation procedure from this work, which was judged based on phenol uptake, occurred at $600{ }^{\circ} \mathrm{C}$ for $15-30 \mathrm{~min}$; the temperature seems to be high enough to promote a substantial desorption of the adsorbed phenol molecules, while at the same time it is minimizing the negative impact of the heat treatment on the porous structure of the adsorbent. Lowering by $200^{\circ} \mathrm{C}$ the high temperatures usually applied in reactivation of activated carbons appears very promising for the economic feasibility of the process itself, suggesting important energy savings.

Steam reactivation at $850{ }^{\circ} \mathrm{C}$ also leads to superior performance of the regenerated carbon, when the treatment is applied for short time (up to $60 \mathrm{~min}$ ). When the reactivation treatment is hold for longer times, the regeneration efficiency starts to decrease due to the gasification -overreactivation- of the carbon material in the steam atmosphere. Steam gasification of the carbon proceeds via the erosion of the pore walls and the widening of the microporosity. 


\section{Acknowledgements}

The authors thank the Bulgarian Academy of Sciences and the Division of International Affaires of CSIC for financial support (grant 2007BG0015). COA thanks the Spanish MICINN for a Ramon y Cajal research contract and the financial support (project CTM2008-01956). BC thanks CSIC for a Marina Bueno fellowship (EST001047)

\section{REFERENCES}

[1] T.J. Bandosz (Ed.) in: Activated carbon surfaces in environmental remediation, Interface science and technology series, Elsevier, New York, 2006.

[2] Dranca, Y. Lupascu, K. Vogelsang, L. Monahova, Utilization of thermal analysis to establish the optimal conditions for regeneration of activated carbons, J. Therm. Anal. Cal. 64 (2001) 945-53.

[3] M. Sheintuch, Y.I. Matatov-Meytal, Comparison of catalytic processes with other regeneration methods of activated carbon, Catal. Today 53 (1999) 73.

[4] D. Bathen, Physical waves in adsorption technology—an overview, Sep. Purif. Technol. 33 (2003), 163-177.

[5] C.O. Ania, J.A. Menendez, J.B. Parra, J.J. Pis, Microwave-induced regeneration of activated carbons polluted with phenol. A comparison with conventional thermal regeneration, Carbon 42 (2004) 1377-1381.

[6] C.O. Ania, J.A. Menendez, J.B. Parra, J.J. Pis, Effect of microwave and conventional regeneration on the microporous and mesoporous network and on the adsorptive capacity of activated carbons, Microp. Mesop. Mat. 85 (2005) 715.

[7] D.W. Mazyck F.S. Cannon, Overcoming calcium catalysis during the thermal reactivation of granular activated carbon: part I. Steam-curing plus rampedtemperature N2 treatment, Carbon 38 (2000) (13), 1785-1799.

[8] D.W. Mazyck F.S. Cannon, Overcoming calcium catalysis during the thermal reactivation of granular activated carbon: part II. Variation of steam-curing reactivation parameters, Carbon 40 (2002) (3), 241-252. 
[9] C. Moreno-Castilla, J. Rivera-Utrilla, J.P. Joly, M.V. Lopez- Ramon, M.A. FerroGarcia, F. Carrasco-Marin, Thermal regeneration of an activated carbon exhausted with different substituted phenols, Carbon 33 (1995) 1417-1423.

[10] T. E. Chestnutt, M. T. Bacha, D.W. Mazyck, Improvement of thermal reactivation of activated carbon for the removal of 2-methylisoborneol, Water Research, 41 (2007) 79-86

[11] M.F. Tennant, D. W. Mazyck, Steam-pyrolysis activation of wood char for superior odorant removal, Carbon 41 (2003) 2195-2202.

[12] J.A. MacKenzie, M.F. Tennant, D.W. Mazyck, Tailored Granular Activated Carbon for the Control of 2-Methlyisoborneol. J. AWWA 97 (2005) 76-87.

[13] Roskill Information Services Ltd. The economics of activated carbon. Clapham Road. SW9 OJA, London, 1998.

[14] C.O. Ania, J.B. Parra, C. Pevida, A. Arenillas, F. Rubiera, J.J. Pis, Pyrolysis of activated carbons exhausted with organic compounds, J. Anal. Appl. Pyrolysis 74 (2005) 518-524.

[15] S.J. Gregg, K.S.W. Sing, in Adsorption Surface Area and Porosity, Academic Press, London, 1982.

[16] F. Stoeckli, L. Ballerini, Evolution of microporosity during activation of carbon, Fuel 70 (1991) 557-560.

[17] F. Rouquerol, J. Rouquerol, K. Sing, in Adsorption by Powders \& Porous Solids, Academic Press, London, 1999.

[18] J.S. Noh, J.A. Schwarz, Estimation of the point of zero charge of simple oxides by mass titration, J. Colloid Interface Sci. 130 (1989) 157-164.

[19] Y. Sekine, K. Ishikawa, E. Kikuchi, M. Matsukata, A. Akimoto, Reactivity and structural change of coal char during steam gasification, Fuel 85 (2006) 122-126.

[20] A.A. Lizzio, H. Jiang, L.R. Radovic, On the kinetics of carbon char gasification: reconciling models with experiments, Carbon, 28, 1990, 7-19.

[21] A.M. Rao, A.W.P. Fung, M.S. Dresselhaus, M. Endo, Structural characterization of heat-treated activated carbon fibers, J. Mater. Res. 7 (1996) 1788-1794. 
[22] M. G. Lussier, Z. Zhang. D.J. Miller, Characterizing rate inhibition in steam/hydrogen gasification via analysis of adsorbed hydrogen, Carbon 36 (1998) 1361-1369.

[23] L.R. Radovic, C. Moreno-Castilla, J. Rivera-Utrilla, Carbon materials as adsorbents in aqueous solutions, in: L.R. Radovic (Ed.), Chemistry and physics of carbon, Basel: Marcel Dekker, New York, 27, 2001, pp. 227-405.

[24] K. Laszlo, E. Tombacz , C. Novak, pH-dependent adsorption and desorption of phenol and aniline on basic activated carbon Colloids and Surfaces A: Physicochem. Eng. Aspects 306 (2007) 95-101.

[25] A.P. Terzyk, Further insights into the role of carbon surface functionalities in the mechanism of phenol adsorption, J. Colloid Interf. Sci. 268 (2003), 301-329.

[26] K.F. Loughlin, M.M. Hassan, E.O. Ekhator, G.F. Nakhla, The adsorption of phenol and its reaction in the presence of oxygen on granular activated carbon, in: M.D. LeVan (Ed.), Fundamentals of Adsorption, Kluwer, Boston, 1996, 537-544.

[27] T.M. Grant, C.J. King, Mechanism of irreversible adsorption of phenolic compounds by activated carbons, Ind. Eng. Chem. Res. 29 (1990) 264-271.

[28] I.I. Salame, T.J. Bandosz, Role of surface chemistry in adsorption of phenol on activated carbons, J. Colloid Interface Sci. 264 (2003) 307-312.

[29] R. Cypres, B. Bettens, Pyrolytic fragmentation mechanisms of phenol and cresols, Tetrahedron 30 (1974) 1253-1260.

[30] S. Cooke, M.M. Labes, Destruction of the environmentally hazardous monochlorinated phenols via pyrolysis in an inert atmosphere, Carbon 32 (1994) $1055-1058$.

[31] G. Socrates, in Infrared Characteristic Group Frequencies, John Wiley \& Sons, Chichester (1980).

[32] S.I. Ayuthaya, N. Mongkolsiri, P. Praserthdam, P.L. Silveston, Carbon deposits effects on the selective catalytic reduction of NO over zeolites using temperature programmed oxidation technique, Appl. Catal. B: Environmental 43 (2003) 1-12. 
Figure 1. DTG profiles of the as-received carbon after steam pyrolysis at different temperatures and time of exposure in the absence of phenol (blank series). The profile of the exhausted carbon (Q exh) is also shown for comparison purposes.
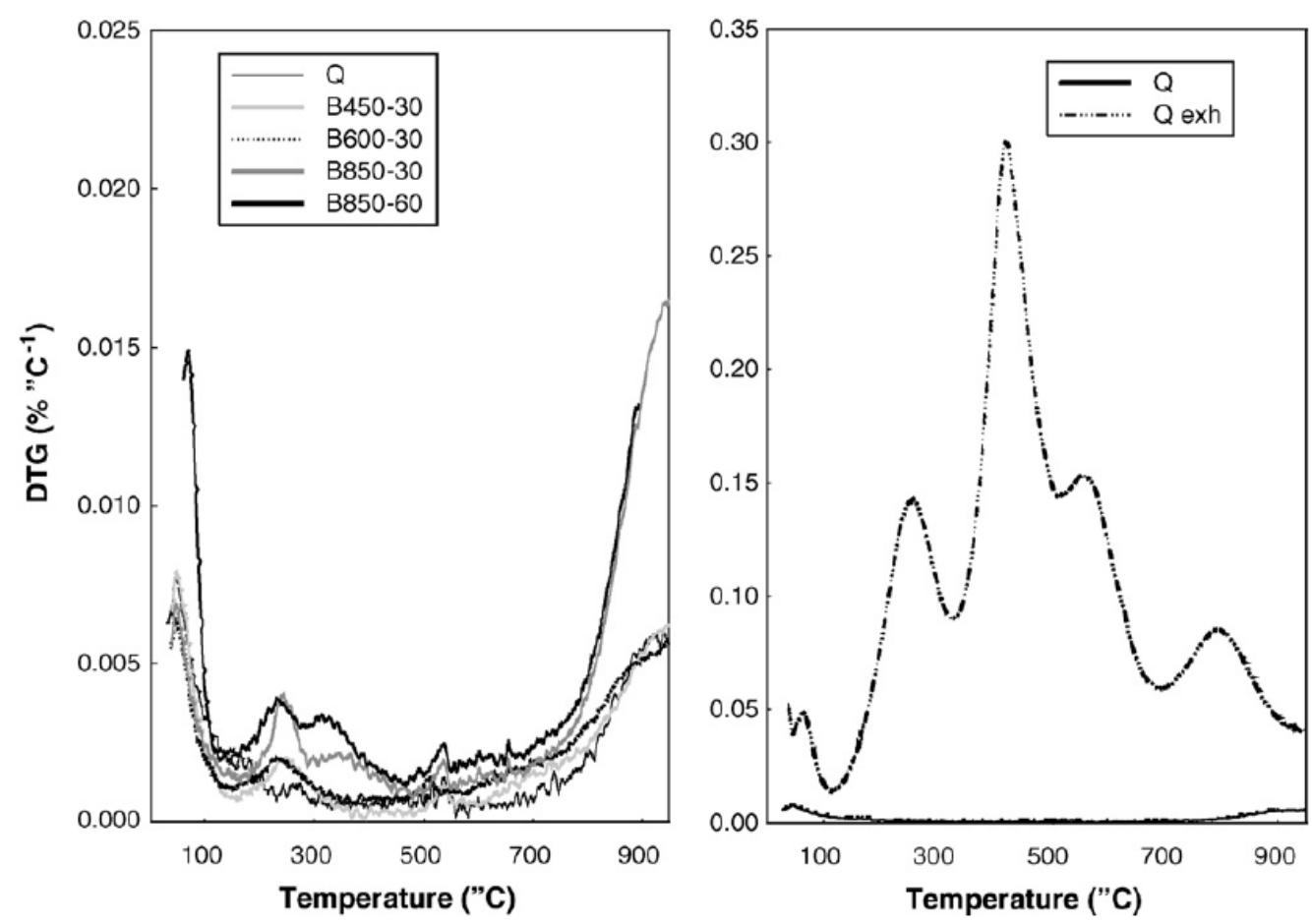
Figure 2. DTG profiles of the as-received (Q), exhausted (Q exh) and reactivated samples at various temperatures and times of exposure.
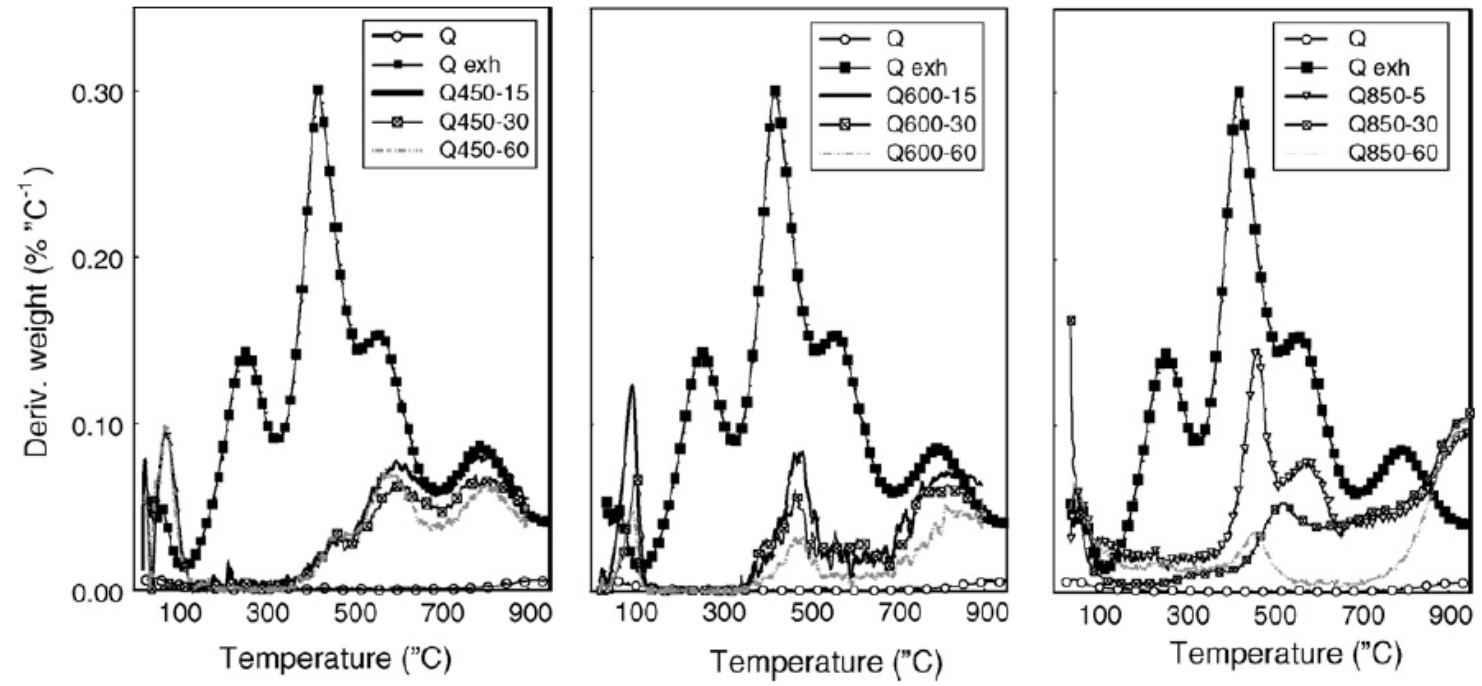
Figure 3. DRIFT spectra of the carbons reactivated at $850{ }^{\circ} \mathrm{C}$ (right $\mathrm{Y}$ axis). For comparison purposes, the spectrum of solid phenol (left $\mathrm{Y}$ axis) is also shown as a reference.

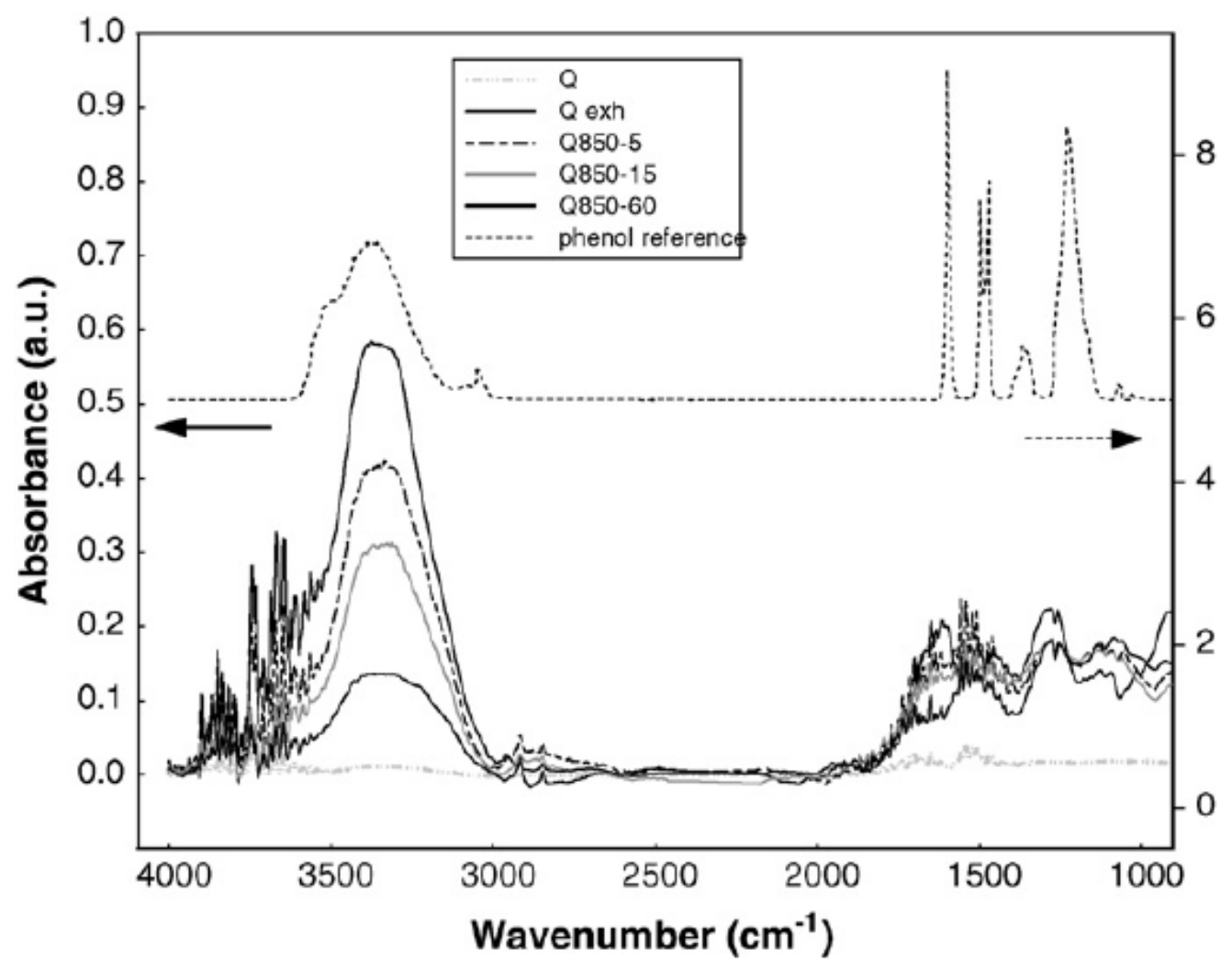


Figure 4. Saturation curves of the activated carbon after reactivation in steam at the different temperatures and times.
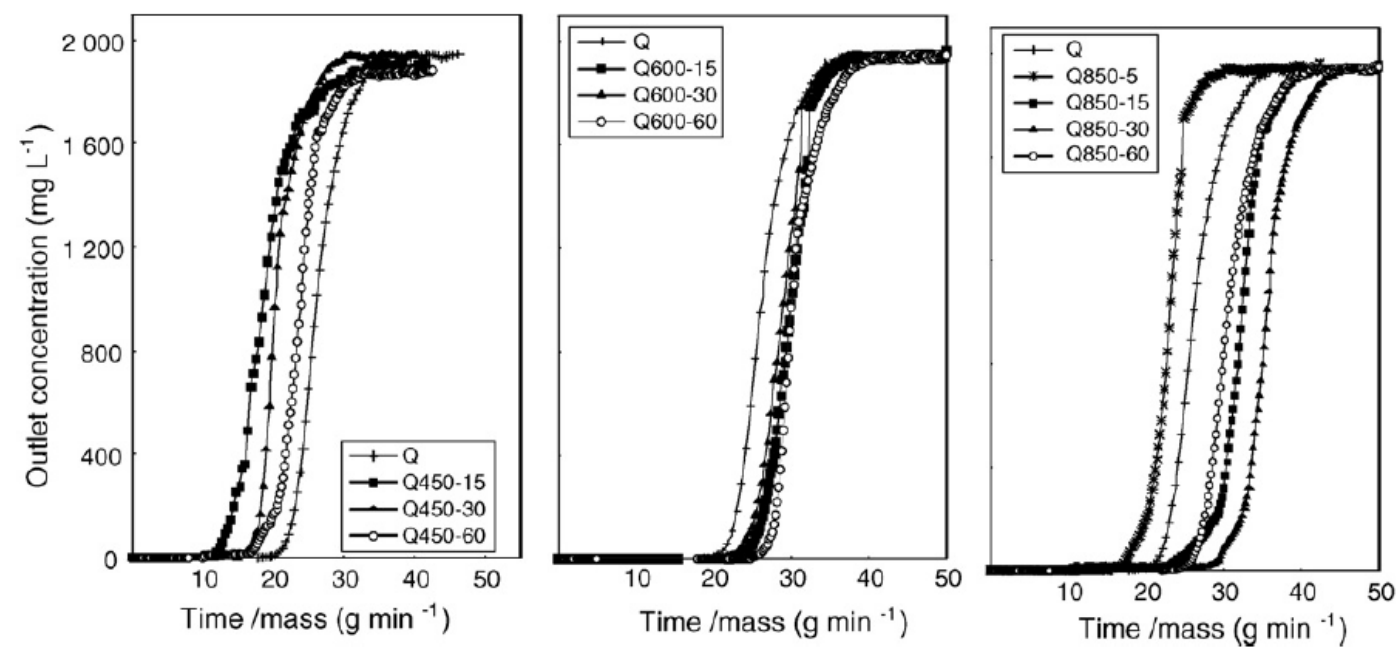
Figure 5. $\mathrm{CO}_{2}$ adsorption isotherms at $0{ }^{\circ} \mathrm{C}$ of the as-received and exhausted carbons after reactivation at different conditions.
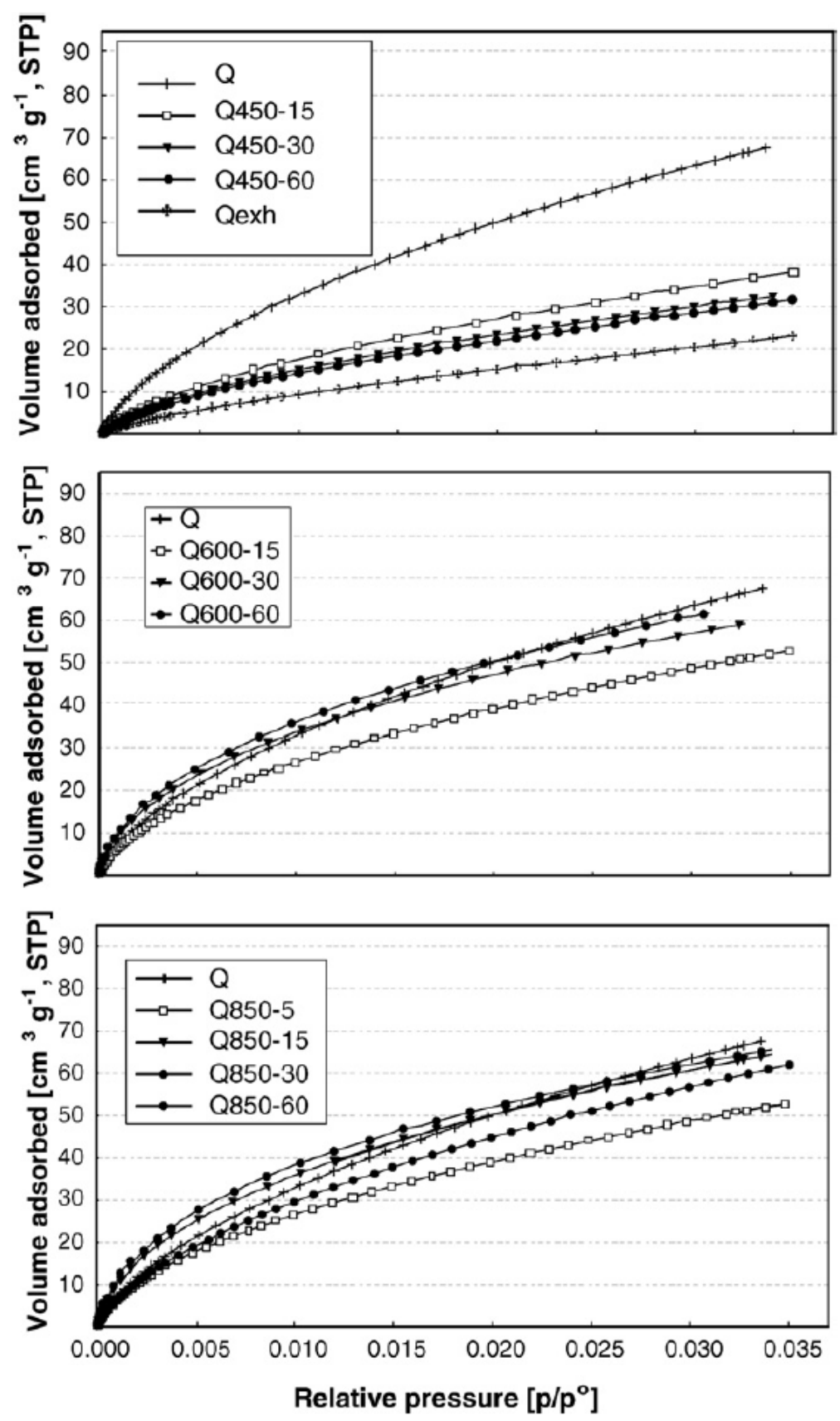
Table 1. Chemical composition of the as-received carbon

\begin{tabular}{ccccccc}
\hline & $\begin{array}{c}\text { Ash } \\
\text { content } \\
\text { (wt. \%) }\end{array}$ & $\begin{array}{c}\text { C } \\
\text { (wt. \%) }\end{array}$ & $\begin{array}{c}\text { H } \\
\text { (wt. \%) }\end{array}$ & $\begin{array}{c}\text { O } \\
\text { (wt. \%) }\end{array}$ & $\begin{array}{c}\text { N } \\
\text { (wt. \%) }\end{array}$ & $\begin{array}{c}\text { S } \\
\text { (wt. \%) }\end{array}$ \\
\hline Q & 11.4 & 85.6 & 0.5 & 1.9 & 0.4 & 0.2 \\
\hline
\end{tabular}

Table 2. Textural parameters of the non-exhausted activated carbon submitted to steam pyrolysis (blank series) evaluated from the DR method applied to the $\mathrm{N}_{2}$ and $\mathrm{CO}_{2}$ adsorption isotherms at -196 and $0{ }^{\circ} \mathrm{C}$, respectively

\begin{tabular}{clcccccc}
\hline $\mathbf{p H}$ & & $\begin{array}{c}\mathbf{S}_{\text {BET }} \\
\left(\mathbf{m}^{2} \mathbf{g}^{-\mathbf{1}}\right)\end{array}$ & $\begin{array}{c}\mathbf{V}_{\text {TOTAL}}, \\
\left(\mathbf{c m}^{\mathbf{3}} \mathbf{g}^{-\mathbf{1}}\right)\end{array}$ & $\begin{array}{c}\mathbf{W}_{\mathbf{o}, \mathbf{N 2}} \\
\left(\mathbf{c m}^{\mathbf{3}} \mathbf{g}^{-\mathbf{1}}\right)\end{array}$ & $\begin{array}{c}\mathbf{S}_{\mathbf{m i c}, \mathbf{N 2}} \\
\left(\mathbf{m}^{\mathbf{2}} \mathbf{g}^{-\mathbf{1}}\right)\end{array}$ & $\begin{array}{c}\mathbf{L} \\
{[\mathbf{n m}]}\end{array}$ & $\begin{array}{c}\mathbf{W}_{\mathbf{o}, \mathbf{C O}} \\
\left(\mathbf{c m}^{\mathbf{3}} \mathbf{g}^{\mathbf{1}} \mathbf{)}\right.\end{array}$ \\
\hline 9.2 & $\mathbf{Q}$ & 1156 & 0.646 & 0.497 & 591 & 1.68 & 0.221 \\
\hline 9.1 & $\mathbf{B 4 5 0 - 1 5}$ & 1031 & 0.534 & 0.387 & 548 & 1.41 & 0.228 \\
9.1 & $\mathbf{B 4 5 0 - 3 0}$ & 1031 & 0.527 & 0.379 & 533 & 1.42 & 0.236 \\
9.0 & $\mathbf{B 4 5 0 - 6 0}$ & 1017 & 0.545 & 0.373 & 540 & 1.38 & 0.236 \\
\hline 8.9 & $\mathbf{B 6 0 0 - 1 5}$ & 1114 & 0.578 & 0.407 & 576 & 1.41 & 0.205 \\
9.1 & $\mathbf{B 6 0 0 - 3 0}$ & 1060 & 0.550 & 0.387 & 548 & 1.41 & 0.206 \\
8.8 & $\mathbf{B 6 0 0 - 6 0}$ & 1090 & 0.558 & 0.398 & 563 & 1.41 & 0.229 \\
\hline 9.1 & $\mathbf{B 8 5 0 - 5}$ & 1210 & 0.646 & 0.421 & 594 & 1.42 & 0.227 \\
8.9 & $\mathbf{B 8 5 0 - 1 5}$ & 1297 & 0.706 & 0.462 & 480 & 1.92 & 0.224 \\
8.6 & $\mathbf{B 8 5 0 - 3 0}$ & 1279 & 0.709 & 0.450 & 492 & 1.83 & 0.229 \\
8.7 & $\mathbf{B 8 5 0 - 6 0}$ & 1341 & 0.813 & 0.472 & 464 & 2.03 & 0.188 \\
\hline
\end{tabular}


Table 3. Mass loss -moisture corrected- of the reactivated samples, evaluated from the DTG profiles

\begin{tabular}{lc|cc}
\hline & $\begin{array}{c}\text { Mass loss } \\
{[\%]}\end{array}$ & & $\begin{array}{c}\text { Mass loss } \\
{[\%]}\end{array}$ \\
\hline Q & 1.6 & Q450-15 & 5.2 \\
Q exh & 10.7 & Q450-30 & 5.2 \\
\hline Q850-5 & 5.3 & Q450-60 & 5.6 \\
\cline { 3 - 4 } Q850-15 & -- & $\mathbf{Q 6 0 0 - 1 5}$ & 3.2 \\
Q850-30 & 2.9 & Q600-30 & 2.5 \\
Q850-60 & 2.2 & Q600-60 & 2.2 \\
\hline
\end{tabular}

Table 4. Textural parameters of the reactivated carbons at different operating conditions, evaluated from the DR method applied to the $\mathrm{N}_{2}$ and $\mathrm{CO}_{2}$ adsorption isotherms at -196 and $0{ }^{\circ} \mathrm{C}$, respectively

\begin{tabular}{|c|c|c|c|c|c|c|c|}
\hline pH & & $\begin{array}{c}S_{\text {BET }} \\
\left(\mathrm{m}^{2} \mathrm{~g}^{-1}\right)\end{array}$ & $\begin{array}{l}\mathrm{V}_{\text {TOTAL }} \\
\left(\mathrm{cm}^{3} \mathrm{~g}^{-1}\right)\end{array}$ & $\begin{array}{c}W_{0, N 2} \\
\left(\mathrm{~cm}^{3} \mathrm{~g}^{-1}\right)\end{array}$ & $\begin{array}{l}S_{\text {mic, } N 2} \\
\left(m^{2} g^{-1}\right)\end{array}$ & $\begin{array}{c}\mathrm{L} \\
{[\mathrm{nm}]}\end{array}$ & $\begin{array}{r}W_{0, C O 2} \\
\left(\mathrm{~cm}^{3} \mathrm{~g}^{-1}\right)\end{array}$ \\
\hline 9.2 & $\mathbf{Q}$ & 1156 & 0.646 & 0.497 & 591 & 1.68 & 0.221 \\
\hline 6.9 & Q exh & 376 & 0.241 & 0.131 & 92 & 2.85 & 0.089 \\
\hline 7.6 & Q450-15 & 630 & 0.362 & 0.238 & 220 & 2.2 & 0.128 \\
\hline 7.8 & Q450-30 & 594 & 0.356 & 0.228 & 208 & 2.2 & 0.118 \\
\hline 8.1 & Q450-60 & 472 & 0.342 & 0.203 & 242 & 1.7 & 0.119 \\
\hline 8.5 & Q600-15 & 782 & 0.425 & 0.308 & 403 & 1.41 & 0.153 \\
\hline 8.7 & Q600-30 & 819 & 0.470 & 0.290 & 443 & 1.31 & 0.173 \\
\hline 8.9 & Q600-60 & 980 & 0.504 & 0.359 & 458 & 1.57 & 0.187 \\
\hline 8.1 & Q850-5 & 518 & 0.501 & 0.332 & 508 & 1.31 & 0.142 \\
\hline 8.4 & Q850-15 & 1040 & 0.58 & 0.382 & 480 & 1.59 & 0.199 \\
\hline 8.9 & Q850-30 & 993 & 0.563 & 0.359 & 449 & 1.6 & 0.202 \\
\hline 9.0 & Q850-60 & 1297 & 0.864 & 0.449 & 362 & 2.5 & 0.213 \\
\hline
\end{tabular}

